\title{
PENGEMBANGAN PENDIDIKAN ISLAM BERKEMAJUAN PERSPEKTIF MUHAMMADIYAH
}

\author{
Ismunandar ${ }^{1 *}$ \\ 1* Magister Pendidikan Agama Islam, Universitas Ahmad Dahlan, Yogyakarta, Indonesia
}

\begin{abstract}
This paper discuses the development of advanced Islamic education in the perspective of Muhammadiyah. The concept of advanced Islam is an

Keyword: opportunity for the challenges of the times to strengthen the strength of

Education Islamic education itself. Muhammadiyah is one of the Islamic socio-

Development, Islam

Berkemajuan,

Muhammadiyah,

Islamic Education

Kata Kunci:

Pengembangan

Pendidikan,

Islam religious organizations in Indonesia that has the spirit of Islamic reform, including part of the modernist Islamic organization in Indonesia. Muhammadiyah brings progressing Islam which carries the mission of building an advanced society in various aspects of life, both in social, social, economic, educational, cultural and political life. Therefore, Muhammadiyah continues to make serious efforts and endeavors tirelessly to create a true Islamic society. This study aims to identify and develop the current advanced Islamic education patterns. This type of research is using the library research method (library research) with data sources in the form of scientific articles, books, policy documents and circulars, journals, and other sources that are library in nature. The data collected was then analyzed in depth with content analysis techniques (Content Analysis) and presented descriptively. The results of the study indicate that advanced Islamic education is needed to be applied in Indonesia. Because the challenges of globalization require expertise on all fronts in responding to the problems of life today. Advancing Islamic education in the perspective of Muhammadiyah is Islamic education that integrates science with Islam. Education that integrates religion in the life of a holistic blend formed between faith and modernity.

Berkemajuan, Muhammadiyah, Pendidikan Islam

ABSTRAK

Tulisan ini mengkaji tentang pengembangan pendidikan Islam berkemajuan dalam perspektif Muhammadiyah. Konsep Islam berkemajuan merupakan peluang dan tantangan zaman untuk meneguhkan kekuatan pendidikan Islam. Penelitian ini bertujuan untuk mengetahui dan mengembangkan pola pendidikan Islam berkemajuan yang ada saat ini. Jenis penelitian merupakan jenis studi kepustakaan (library research) dengan sumber data berupa artikel ilmiah, buku, dokumen kebijakan maupaun surat edaran, jurnal, serta sumbersumber lain yang bersifat kepustakaan. Data yang dikumpulkan kemudian dianalisis secara mendalam dengan teknik analisis isi (Content Analysis) dan disajikan secara deskriptif. Hasil penelitian menunjukkan bahwa pendidikan Islam berkemajuan sangat diperlukan untuk senantiasa diterapkan di Indonesia. Sebab tantangan globalisasi yang ada menuntut kepiawian dalam semua lini dalam menjawab masalah-masalah kehidupan saat ini. Pendidikan Islam berkemajuan dalam perspektif Muhammadiyah merupakan pendidikan Islam yang mengintegrasikan ilmu pengetahuan dengan Islam. Pendidikan yang mengintegrasikan agama dalam kehidupan membentuk perpaduan yang holistik antara iman dan kemodernan.
\end{abstract}

\section{INTRODUCTION}

Pendidikan Islam adalah upaya sadar dalam mengembangkan potensi-potensi yang ada pada peserta didik secara maksimal. Sistem pendidikan dapat mengubah, mengarahkan atau bahkan membentuk manusia sesuai dengan tahap perkembangannya. Usaha membentuk diri manusia diperlukan keseriusan semua komponen yang ada dalam diri manusia itu sendiri. Selama manusia mau merubah untuk sebuah tujuan hidup yang mulia dan berkemajuan tentu menjadikan semangat 
dalam mencapai cita-citanya.

Pendidikan Islam perspektif Islam berkemajuan yaitu merupakan pendidikan Islam yang mengitegrasikan ilmu pengetahuan dan agama. Pendidikan yang mengintegrasikan agama dengan kehidupan dan antara iman dan kemajuan yang holistik. Konsep pendidikan Islam perspektif Islam berkemajuan yaitu sebagai refleksi nilai-nilai humanisasi, liberasi, emansipasi dan transendensi dari kandungan Q.S Ali Imran ayat 104 dan 110. Pendidikan Islam perspektif Islam berkemajuan yaitu; Pertama, humanisasi sebagai pendidikan yang membawa tranformasi sosial menuju tranformasi intelektual dan proses pembangunan karakter kemanusiaan. Kedua, liberasi yaitu pendidikan yang mampu menyadarkan masyarakat akan realitas sosial yang sudah terkontaminasi dengan budaya lokal (khususnya Hindu dan Budha). Selain itu membentuk generasi muda menjadi individu yang berpikiran maju atau modern, terhindar dari kejumudan pemikiran. Ketiga emansipasi merupakan pembebasan perbudakan, atau per-samaan hak baik laki-laki maupun perempuan. Pendidikan Islam perspektif Islam berkemajuan memberikan kebebasan untuk individunya berkembang dan memanfaatkan potensi diri. Serta tidak adanya diskriminasi terhadap kaum perempuan. Keempat, transendensi (proses mempercayai yang bernuansa abstrak, ghaib). Pendidikan Islam perspektif Islam berkemajuan menyeimbangkan pendidikan yang diperoleh peserta didik dengan lebih menekankan kepada pembinaan moralitas untuk awal pembentukan kerpibadian yang sempurna (insan kamil) dan menjadi individu yang rahmatan lil alamin (Hanipuddin, 2020).

Pendidikan Islam perspektif Islam berkemajuan bila dilihat secara ideologis, merupakan bentuk transformasi Al Ma'un untuk menghadirkan dakwah dan tajdid secara aktual dalam pergulatan hidup keutamaan, kebangsaan dan kemanusian universal. Pendidikan Islam perspektif Islam berkemajuan diharapkan mampu menyeimbangkan dan memaksimalkan peran manusia untuk kebaikan dunia dan akhirat.

Banyak penelitan yang telah mengkaji tentang pendidikan Islam berkemajuan dalam perspektif Muhammadiyah. Menurut Sarno Hanipudin mengkaji pendidikan Islam berkemajuan dalam pemikiran Haedar Nashir. Penelitian Sarno menyimpulkan bahwa dalam pandangan Muhammadiyah, Islam merupakan agama yang mengandung nilai-nilai kemajuan untuk membangun peradaban yang utama dan menjadi rahmat bagi semesta. Inilah yang disebut Islam berkemajuan atau din al-Hadlarah. "Kemajuan dalam pandangan Islam bersifat multiaspek baik 
dalam kehidupan keagamaan maupun dalam seluruh dimensi kehidupan termasuk didalamnya pendidikan islam yang melahirkan peradaban utama sebagai bentuk peradaban alternatif yang unggul secara lahiriah dan ruhaniah (Hanipuddin, 2020). Mundzirin, dkk mengkaji tentang Islam berkemajuan dalam perspektif Muhammadiyah. Penelitian ini berkesimpulan bahwa aktualisasi hasil muktamar Muhammadiyah pasca muktamar ke 47. Dua penelitian ini belum membahas tentang pendidikan Islam berkemajuan perspektif Muhammadiyah.

Berdasarkan latar belakang tersebut, penelitian ini membahas Bagaimanakah pandangan Muhammadiyah dalam konsep pendidikan Islam yang berkemajuan? Bagaimana pengembangan dari konsep-konsep tersebut? Tulisan ini didasarkan pada argumentasi bahwa Muhammadiyah sebagai organisasi Islam yang telah berkiprah 108 tahun ini telah membantu keberlangsungan dalam berbagai bidang bagi Indonesia dan yang paling popular adalah dalam bidang pendidikan. Dalam amal usaha dalam bidang pendidikan baik dari tingkat TK/MI, SMP/MTs, SMA/MK dan Perguruan tinggi berjumlah 16.452 lembaga. Dengan jumlah yang ada ini tentu mampu memberikan layanan dalam duni pendidikan semaksimal mungkin agar tercapainya SDM yang unggul dan berkualitas. Sehingga sangat diharapkan bukti-bukti keberhasilan lembaga pendidikan Islam berkemajuan bagi bangsa ini.

\section{METODE PENELITIAN}

Penelitian ini adalah kajian kepustakaan (Library research) dimana sebagai cara untuk menggali informasi atau data yang bersumber dari karya ilmiah, artikel jurnal buku, dan sumber lainnya yang bersifat kepustakaan. Metode yang digunakan yakni kualitatif deskriptif dengan analisis isi (Content Analysisi) dimana memaparkan secara mendalam terhadap ini atau informasi yang termuat didalam sumber data. Pengumpulan data dilakukan dengan cara mengumpulkan kajian-kajian yang terkait dengan penelitian yang kemudian disajikan secara deskriptif.

Sumber data primer penelitian ini adalah organisasi Muhammadiyah tentang pandangan dunia pendidikan mereka untuk pendidikan Islam yang berkemajuan. Data sekunder adalah dari internet, suara Muhammadiyah dan surat kabar lainnya yang mendukung daripada tulisan ini.

\section{HASIL DAN PEMBAHASAN}

\subsection{Pendidikan Islam Berkemajuan}

Pendidikan Islam yaitu sebuah proses yang dilakukan untuk menciptakan manusia-manusia yang sutuhnya; beriman dan bertakwa kepada Tuhan serta mampu mewujudkan eksistensinya sebagai khalifah dibumi. Kata'Islam" dalam "Pendidikan Islam' menunjukkan itu pendidikan tertentu, yaitu pendidikan yang khusus mencakup hal-hal yang berkaitan dengan Islam. Pendidikan adalah bimbingan atau pimpinan secara sadar oleh pendidik terhadap perkembangan jasmani dan rohanbi anak didik menujku terbentuknya kepribadian yang utama (Tafsir, 2010). Sedangkan kata" Pendidikan" dalam Bahasa Arab berkaitan atau dekat dengan tiga tema, yaitu ta'lim, tarbiyah atau 
ta'dib (Shobron, 2009:266). Kata ta'lim lebih condong pada aspek pengetahuan kognitif, tarbiyah lebih menekankan pada pemeliharaan dan asuhan dengan kasih sayang, dan ta'dib menekankan pada aspek kognitif, afektif, dan psikomotorik (Shobron, 2009: 279). Jadi pendidikan Islam merupakan segala usaha untuk memelihara dan mengembangkan fitrah serta daya insani yang ada padanya menuju terbentuknya manusia seutuhnya (insan kamil) sesuai dengan norma Islam.

Pendidikan Islam sejak awal perkembangannya telah berdiri tegak diatas dua sumber pokok yang amat penting yaitu Al Qur'an dan Sunnah Nabi. Didalam kitab suci terkandung ayat mufasshalaat (terinci) dan ayat-ayat Mubayyinat (yang memberikan bukti-bukti kebenaran) yang mendorong kepada orang untuk belajar membaca dan menulis serta untuk menuntut ilmu, memikirkan, merenungkan dan menganalisis ciptaan langit dan bumi. Oleh karena itu maka tujuan da'wah Islamiyah adalah untuk memberi cahaya terang kepada hati nurani dan pikiran serta menambah kemampuan umat Islam dalam melakukan proses pengajaran dan pendidikan. Karena Rasulullah SAW sendiri diutus pertama-tama untuk menjadi pendidik dan beliau adalah guru yang pertama dalam Islam.

Dalam buku "Indonesia berkemajuan" ditegaskan, bahwa Muhammadiyah sebagai kekuatan nasional sejak awal berdirinya pada tahun 1912 telah berjuang dalam pergerakan kemerdekaan dan melalui para tokohnya terlibat aktif mendirikan Negara Republik Indonesia yang diproklamasikan pada 17 Agustus 1945. Muhammadiyah memiliki kopmitmen dan tanggung jawab tinggi untuk memajukan kehidupan bangsa dan negara sebagaimana dicita-citakan para pendiri bangsa. Kiprah Muhammadiyah tersebut melekat dengan nilai dan pandangan Islam yang bekemajuan.

Pendiri Muhammadiyah sejak awal pergerakannya senantiasa berorientasi pada sikap dan gagasan yang berkemajuan. Sebab, Muhammadiyah sungguh-sungguh percaya bahwa Islam merupakan agama yang mengandung nilai-nilai kemajuan. Islam adalah agama kemajuan (din alhadlarah) yang diturunkan untuk meujudkan kehidupan umat manusia yang tercerahkan dan membawa rahmat bagi semesta alam.

Munculnya gerakan Islam berkemajuan juga digelorakan pada Muktamar ke-46 tahun 2010 di Yogyakarta, bahwa Muhammadiyah pada abad kedua berkomitmen kuat untuk melakukan gerakan pencerahan. Gerakan pencerahan merupakan praksis Islam yang berkemajuan untuk membebaskan, memberdayakan, dan memajukan kehidupan. Tujuan dari gerakan Islam berkemajuan ini adalah untuk memberikan jawaban atas problem-problem kemanusiaan berupa kemiskinan, kebodohan, ketertinggalan, dan persoalan-persoalan lainnya yang bercorak struktural dan kultural, dari sini muncul konsep berkemajuan disegala bidang termasuk didalam pendidikan Islam (Muhammadiyah, 2010).

Pendidikan Islam berkemajuan merupakan pendidikan Islam yang mengitegrasikan dikotomi ilmu pengetahuan. Pendidikan yang mengintegrasikan agama dengan kehidupan dan antara iman dan kemajuan yang holistik. Konsep pendidikan Islam berkemajuan sebagai refleksi 
nilai-nilai Humanisasi, Liberasi dan Transendensi dari kandungan Q.S Ali Imran ayat 104 dan 110 (Hanipuddin, 2020).

\subsection{Pendidikan Islam Berkemajuan Perspektif Muhammadiyah}

Pendidikan Islam adalah usaha membimbing, mengarahkan, dan membina peserta didik yang dilakukan secara sadar dan terencana agar terbina suatu kepribadian yang utama sesuai dengan nilai-nilai ajaran Islam. Tujuan ini secara herarkhis bersifat ideal bahkan universal. Tujuan tersebut dapat dijabarkan pada tingkat yang lebih rendah lagi, menjadi tujuan yang bercorak nasional, institusional, terminal, klasikan, perbidang studi, berpokok ajaran, sampai dengan setiap kali melakasanakan kegiatan belajar mengajar.

Dengan pengembangan makna dan komitmen pendidikan, maka sesorang akan termotivasi untuk berprestasi, mempunyai semangat mencipta, menemukan, berinovasi yang bersumber kepada semangat percobaan dan semangat kritis. Sedangkan dengan pengembangan tujuan dan pengarahan pendidikan, anak didik diharapkan tidak hanya mengikuti logika dalam mengembangkan ilmu dan teknologinya sehingga tidak menyebabkan kerusakan alam karena penggalian sumber daya alam yang berlebihan, pencemaran lingkungan hidup, perlombaan senjata, ketidak-adilan sosial, ekonomi, pelanggaran hak asasi manusia, perkembangan budaya kekerasan, dan lain-lain.

Pendidikan Islam yang berkemajuan dalam perspektif Muhammadiyah berawal dari pemikiran pendirinya yakni KH Ahmad Dahlan agar umat Islam selamat, oleh karena itu dengan pendidikan menyelamatkan umat Islam dari cara berpikir statis menuju pemikiran yang dinamis, kreatif dan inovatif, itu merupakan satu-satunya jalan mencapai tujuan tersebut dan melalui pendidikan dan pengolahan pendidikan agama Islam secara modern dan professional, sehingga pendidikan yang dilaksanakan mampu memenuhi atau menghadapi dinamika pada zamannya.

Menurut KH. Ahmad Dahlan, pendidikan yang baik adalah pendidikan yang sesuai dengan tuntunan zaman dan Moderenitas (Mubaroq et al., 2020). Dikisahkan bahwa pada awal abad 20 Ahmad Dahlan melihat umat Islam Indonesia tertinggal secara ekonomi disebabkan oleh kolonialisme Belanda. Ketika itu ekonomi Muslim sangat tidak mempunyai akses ke sektor-sektor pemerintahan atau perusahaan-perusahaan swasta. Karena partisipasi muslim yang rendah terhadap sektor-sektor pemerintahan itu membuat kebijakan pemerintahan kolonial Belanda menutup akses bagi Muslim untuk masuk. Peristiwa ini mendorong Ahmad Dahlan untuk memperbaiki dengan memberikan pencerah tentang pendidikan yang sesuai dengan perkembangan zaman (Nata, 2005).

Pendidikan ideal yang sesuai dengan perkembangan zaman dimulai dari proses belajar yang terdiri dari kesatuan aktivitas yang tak terpisahkan dari kehidupan manusia, yang dapat terjadi dimanapun berada. Seperti di lingkungan keluarga, masyarakat sekolah, kerja dan lain sebagainya. Proses belajar tersebut dinamakan sebagai pendidikan.

Islam mengenal pendidikan dengan pengertian yang menyeluruh yaitu sebagai pengembangan jasmani, akal, rohani, emosi dan akhklak. Islam memandang bahwa pendidikan tidak hanya dapat diperoleh di sekolah namun bisa di luar sekolah. Seperti dirumah, di lingkungan 
masyarakat, di jalan dan lain-lain. Pendidikan itu sendiri dapat diartikan sebagai pemindahan pengetahuan dari generasi tua ke generasi muda untuk menjaga pengetahuan yang ada atua bisa disebut sebagai transfer ilmu. Terdapat dua bentuk pendidikan di masyarakat; 1) pendidikan umum; dan 2) pendidikan agama. Dengan jumlah penduduk Indonesia mayoritas beragama Islam, pendidikan agama Islam mempunyai peran besar dalam kehidupan sehari-hari masyarakat. Selain itu, Masyarakat juga membutuhkan pendidikan umum namun juga membutuhkan pengetahuan agama sebagai bekal hidup dan kehidupan..

Aktivitas pendidikan Islam ada sejak adanya manusia itu sendiri (Nabi Adam dan Hawa), bahkan ayat Al Qur'an yang pertama kali diturunkan kepada Nabi Muhammad SAW adalah perintah Iqra' (membaca, merenungkan, menelaah, meneliti, mengkaji) atau perintah untuk mencerdaskan kehidupan manusia yang merupakan inti dari aktivitas pendidikan (Mujib, 1993). Hingga sekarang eksistensi pendidikan Islam terus menjadi hal yang menarik untuk didiskusikan.Pendidikan islam yaitu sebuah proses yang dilaksanakan untuk menciptakan manusiamanusia yang seutuhnya. Beriman dan bertakwa kepada Tuhan serta mampu meujudkan eksistensinya sebagai khalifah di bumi. Kata "Islam" dalam Pendidikan Islam menunjukkan itu pendidikan tertentu, yaitu pendidikan yang khusus mencakup hal-hal yang berkaitan dengan Islam.

Menurut Muhammad Quthb pendidikan Islam adalah usaha untuk melakukan pendekatan yang mneyeluruh terhadap wujud manusia, baik dari segi jasmani maupun ruhani, baik dari kehidupan fisik maupun mentalnya dalam melaksanakan kegiatannya di bumi ini. Beliau memandang pendidikan Islam sebagai suatu aktifitas yang berusaha memahami diri manusia secara total melalui berbagai pendekatan dalam rangka menjalankan kehidupan dunia. Beda lagi menurut pandangan Achmadi, bahwa pendidikan Islam merupakan segala usaha untuk memelihara dan mengembangkan fitrah serta sumber daya insani yang ada padanya menuju terbentuknya manusia seutuhnya (insan kamil) sesuai dengan norma Islam Rumusan definisi ini menggambarkan upaya mengarahkan kepada pengembangan fitrah dan pembentukan manusia seutuhnya yang sesuai dengan norma Islam (Abdullah et al., 2001). Segala usaha atau ikhtiar dilakukan untuk memelihara dan mengembangkan fitrah dan sumber daya insani.

Dalama melaksanakan pendidikan Islam juga tidak terlepas dari sebuah landasan yang baik dan kuat. Oleh karena itu pendidikan Islam sebagai usaha membentuk manusia, harus memiliki landasan yang jelas kemana semua kegiatan dan semua perumusan tujuan pendidikan Islam itu dihubungkan (Daradjat, 2017). Dasar Pendidikan Nasional terdapat dalam UU No.20 Tahun 2003 tentang Sistem pendidikan Nasional tercantum bahwa Pendidikan Nasional berdasarkan Pancasila dan Undang-undang Daasar Negara Republik Indonesia Tahun 1945. Secara yuridis lembaga pendidikan Islam semakin kokoh setelah terbit UU No.2 Tahun 1989 yang secara eksplisit menyebutkan pendidikan keagamaan termasuk dalam Sisdikna (Pasal 11 dan 39) hal ini dikuatkan dalam UU No.20 tahun 2003, pasal 15, 17, 18,30, dan 37 (Rohyani, 2015). Dengan kekuatan tersebut diharapkan perkembangan kemajuan pendidikan Islam akan semakin meningkat. Sedangkan pendidikan Islam sejak awal perkembangannnya telah berdiri tegak diatas dua saumber 
pokok yang amat penting yaitu Al Quran dan Sunnah Nabi. Dalam kitab suci ini terkandung ayat ayat mufassshalat (terinci) dan ayat-ayat Mubayyinat (yang memberikan bukti-bukti kebenaran) yang mendorong kepada orang untuk belajar membaca dan menulis serta untuk menun tut ilmu, memikirkan, merenungkan dan menganalisis ciptaan langit dan bumi. Oleh karena itu maka tujuan da'wah Islamiyah adalah untuk memberi cahaya terang kepada hati nurani dan pikiran serta menambah kemampuan umat Islam dalam melakukan proses pengajaran dan pendidikan. Karena rasulullah saw sendiri diutus pertama-tama untuk menjadi pendidik dan beliau adalah guru yang pertama dalam Islam. Menurut landasan atau dasar dari pendidikan Islam adalah Al-Qur'an, Assunah, Al-kaun (ayat-ayat kauniyah) dan ijtihad (berpikir dengan menggunakan seluruh ilmu yang dimiliki oleh ilmuwan syari'at Islam untuk menetapkan dan menentukan sesuatu hukum syariat Islam dalam hal-hal yang ternyata belum ditegaskan hukumnya oleh Al- Qur'an dan As Sunnah. Pendidikan Islam berkemajuan dalam perspektif Muhammadiyah juga berlandaskan empat hal diatas (Rosyadi \& Kuswaidi, 2004).

Kemudian Islam berkemajuan menurut Muhammadiyah, Islam adalah agama Allah yang diwhyukan kepada Rasul-Nya sejak zaman Nabi Adam, Nbai Ibrahim, Nabi Musa, Nabi Isa sampai kepada Nabi Muhammad SAW, sebagai hidayah dan rahmat Allah kepada umat manusia sepanjang masa dan spiritual, duniawi dan Ukhrawi Islam merupakan agama yang menimani satu Tuhan yaitu Allah. Islam sebagai salah satu agama yang mayoritas dipeluk oleh penduduk Indonesia. Islam secara Bahasa (etimologi) yaitu berserah diri, tunduk, atau patuh. Agama Islam sebagai agama yang terakhir dan agama Islam mengakhiri dan menyempurnakan agama sebelumnya yang dianut hamab-Nya. Agama Islam adalah agama yang dibawa oleh Nabi Muhmmad yaitu nabi akhir zaman, Islam ialah ajaran yang diturunkan Allah yang tercantum dalam AlQur'an dan As Sunnah yang shahih berupa perintah-perintah, larangan-larangan, dan petunjuk-petunjuk untuk kebaikan hidup manusia didunia dan akhirat. Ajaran Islam bersifat menyeluruh yang satu dengan yang lainnya tidak dapat dipisah-pisahkan yang meliputi bidang-bidang akhlak, ibadah dan muamalah duniawiyah. Islam adalah agama semua nabi-nabi, agama yang sesuai dengan fitrah manusia, agama yang mengatur hubungan manusia dengan Tuhan dan hubungan manusia dengan manusia, agama yang menjadi rahmat bagi semesta alam(Muhammadiyah, 2010).

Selain itu Islam merupakan agama yang benar dan satu-satunya agama yang diterima Allah, hal ini sesuai dengan firman Allah dalam surat Al-Imran ayat 19: Sesungguhnya agama(yang benar disisi Allah adalah Islam. Islam memiliki keistimewaan diantara agam sebelum-sebelumnya yaitu agama Islam bersifat universal dan sesuai untuk setiap masa, tempat dan kondisi ummat. Selain itu juga sebagai agama satu-satunya yang dibenarkan Allah mencakup seluruh aspek kehidupan seperti: akhlak, ekonomi, sosial, budaya, pendidikan dan lain sebagainya.

Konsep pendidikan Islam berkemajuan perspektif Muhammadiyah, bisa dilihat dari sejarah berdirinya pada tahun 1912 menegaskan disi sebagai Islam yang berjuang menyebarluaskan dan memajukan ajaran Islam di Indonesia yang diilhami oleh firman Allah SWT dalam surat Al-imran ayat 104. Misi Muhammadiyah tersebut dikenal dengan gerakan dakwah dan tajdid. Identitas 
Muhammadiyah ini tercantum dalam Anggaran Dasar muhammadiyah pasal 1 ayat 1 dinyatakan sebagai gerakan Islam dan dakwah amar ma'ruf nahi munkar, beraqaidah Islam dan bersumber kepada Al Qur'an dan As Sunnah. Organisasi yang didirikan oleh K.H Ahmad Dahlan pada tanggal 18 November 1912 ini semakin berkembang, semangat K.H Dahlan ini membuat generasi penerus dibawahnya termotivasi. Usaha yang dilakukan pun telah membuktikan pelaksanaan misi dakwah dan tajdid itu, seperti pembaharuan pemahaman agama, pendirian lembaga pendidikan Islam modern, reformasi system pendidikan Islam, pengembangan pranata pelayanan-pelayanan sosial, dan lain sebagainya. Istilah Islam berkemajuan yang kini menjadi slogan Muhammadiyah kerap digunakan diberbagai momen tertentu yang dilaksanakan oleh Muhammadiyah, Angkatan Muda Muhammadiyah, Amal Usaha Muhammadiyah dan lain sebagainya.

Muhammadiyah memandang bahwa Islam merupakan agama yang mengandung nilai-nilai kemajuan untuk mewujudkan kehidupan manusia yang tercerahkan. Kemajuan dalam pandangan Islam adalah kebaikan yang serba utama, yang melahirkan keunggulan hidup lahiriah dan ruhaniah. Dalam perspektif Muhammadiyah, Islam merupakan agama yang berkemajuan (sin al hadlarah), yang kehadirannya membawa rahmat bagi semesta kehidupan. Islam berkemajuan ini melingkupi segala aspek kehidupan salah satunya yaitu pendidikan. Pendidikan memang sebagai permasalahan yang tidak akan pernah usai. Khusus di bidang pendidikan, umat Islam semakin memerlukan lembaga pendidikan Islam yang inovatif dan berkualitas unggul seiring dengan kelompok kelas menengah muslim yang semakin luas. Pendidikan Islam yang lebih inovatif, unggul, sejalan dengan kepentingan umat dan mengikuti perkembangan zaman yang semakin kompetitif, pendidikan seperti itulah yang masyarakat harapkan. Kemajuan di bidang pendidikan memang tidak bisa instan, tetapi itu bisa diusahakan dengan perlahan.

Di dalam persyarikatan Muhammadiyah, pendidikan berada dibawah naungan Majelis pendidikan Dasr dan Mnegah (Dikdasmen) dan Majelis pendidikan Tinggi (Dikti). Majelis Dikdasmen mengurusi lembaga pendidikan dasar dan pendidikan menegah yang dimiliki Muhammadiyah. Sedangkan Majelis Dikti adalah lembaga yang mengurusi pendidikan tinggi yaitu perguruan Tinggi Muhammadiyah (PTM). Majelis-majelis ini terfokus kepada pengembangan pendidikan seperti: kemajuan sarana dan prasarana pendidikan, administrasi pergedungan, manajemen kurikulum, dan silabusnya. Selain itu melalui pendidikan Majelis Dikdasmen dan Dikti juga mengharapkan adanya akdemisi Islam yang anggun dalam moral, unggul dalam intelektual.

Pendidikan Islam perspektif Islam berkemajuan bila dilihat secara teologis merupakan refleksi dari nilai-nilai transendensi, liberal, emansipasi dan humanisasi yang terkandung dalam pesan Al Qur'an surah Al-Imran ayat 104 dan 110 yang menjadi inspirasi kelahiran Muhammadiyah. Pertama, humanisasi (kemanusiaan) pendidikan Islam perspektif Islam berkemajuan yaitu pendidikan yang membawa transformasi sosial menuju tranformasi intelektual dan proses pembangunan karakter kemanusiaan. Pendidikan Islam perpsektif Islam berkemajuan ditinjau dari aspek sosial sebagai pendidikan yang peduli kepada permasalahan social seperti lingkungan masyarakat, kemiskinan, dan masalah sosial lainnya. Pendidikan Islam perspektif Islam 
berkemajuan adalah pendidikan pencerahan kesadaran ke-Tuhanan (makrifat iman/tauhid) yang menghidupkan, mencerdaskan, dan membebaskan manusia dari kebodohan dan kemiskinan bagi kesejahteraan dan kemakmuran manusia dalam kerangka kehidupan berbangsa dan tata pergaulan dunia yang terus berubah dan berkembang.

Kedua, Liberasi (pembebasan) pendidikan Islam perspektif Islam berkemajuan yaitu pendidikan yang mampu menyadarkan masyarakat akan realitas sosial yang sudah terkontaminasi dengan budaya lokal (khususnya Hindu dan Budha). Akibatnya banyak ibadah-ibadah sacral dalam Islam sudah jauh dari nilai-nilai syariat Islam. Seperti adanya takhayul, bid'ah dan khurafat. Pendidikan Islam pespektif Islam berkemajuan ini menciptakan individu yang bersih dari takhayul, bid'ah dan khurafat serta memiliki cara pandangan ke depan yang lebih kreatif, inovatif. Pendidikan Islam perspektif Islam berkemajuan tersebut berorientasi kepada pendidikan modern yang terinspirasi dari pendidikan Muhammadiyah yang dipelopori oleh K.H Ahmad Dahlan. Pendidikan modern yang memberi ruasng seluas-luasnya bagi perubahan. Pendidikan Islam perspektif berkemajuan yaitu pendidikan yang tidak terjebak pada situasi kemunduran dan keterpurukan. Pendidikan Islam yang mampu menjadi wadah bersama untuk membina generasi muda penerus Islam. Ketiga, Emansipasi merupakan pembebasan perbudakan, atau persamaan hak baik laki-laki maupun perempuan. Pendidikan Islam perspektif Islam berkemajuan memberikan kebebasan untuk individunya berkembang dan memanfaatkan potensi diri. Serta tidak adanya diskriminasi terhadap kaum perempuan.Keempat, Transedensi (proses mempercayai yang bernuasa abstrak, ghaib). Pendidikan Islam perspektif Islam berkemajuan menyeimbangkan pendidikan yang diperoleh peserta didik dengan lebih menekankan kepada pembinaan moralitas untuk awal pembentukan kepribadian yang sempurna (insan kamil) (Hanipuddin, 2020).

Sedangkan pendidikan Islam perspektif Islam berkemajuan bila dilihat secara ideologis, merupakan bentuk transformasi Al Ma'un untuk menghadirkan dakwah dan tajdid secara actual dalam pergulatan hidup keutamaan, kebangsaan dan kemanusiaan universal. Pendidikan Ilsam perpsektif Islam berkemajuan harus mampu menyeimbangkan dan memaksimalkan peran manusia untuk dunia dan akhirat. Pendidikan Muhammadiyah merupakan pendidikan Islam yang modern yang mengintegrasikan agama dengan kehidupan dan antara iman dan kemajuan yang holistik. Dari pendidikan Islam inilah akan lahir generasi muslim terpelajar yang kuat iman dan kepribadiannya, sekaligus mampu menghadapi dan menjawab tantangan zaman. Inilah pendidikan Islam yang berkemajuan (Muhammadiyah, 2010).

Selanjutnya dari segi pelaksanaan, pendidikan Islam perspektif Islam berkemajuan merupakan pendidikan yang menggunakan kurikulum integral yaitu dengan melakukan integrasi keilmuan anatar ilmu agama dan ilmu umum. Sehingga tidak terjadi adanya dikotomi ilmu. Pendidikan Islam perspektif Islam berkemajuan menggunakan system pendidikan modern yang mencegah terjadinya kejumudan pemikiran.

Dasar pendidikan Islam berkemajuan perspektif Muhammadiyah dilandaskan pada Al Qur'an dan As Sunah. Dimana kedua sumber ini menjadi landasan yang kuat karena sebagai acuan pendidikan 
Islam haru merupakan sumber nilai kebenaran dan kekuatan yang menghantarkan pada aktivitas yang dicita-citakan. Pendidikan Islam perspektif Islam berkemajuan terinspirasi dalam Q.S Al Alaq/96:1-5.

Pendidikan Muhammadiyah didasarkan atas nilai-nilai sebagai berikut: pertama, pendidikan Muhammadiyah diselenggarakan merujuk pada Al Qur'an dan As Sunnah. Kedua, niat ikhlas untuk mencari ridho Allah SWT. Ketiga, menerapkan prinsip kerjasama dan tetap memelihara sikap kritis. Keempat, menggunakan prinsip tajdid serta inovasi. Kelima, memiliki kultur untuk selalu memihak kepada kaum yang mengalami kesengsaraan. Keenam, prinsip terakhir yaitu prinsip keseimbangan dalam mengelola lembaga pendidikan antara akal sehat dan kesucian hati (Muhammadiyah, 2010). Dr. Said ismail Ali berpendapat bahwa dasar ideal pendidikan Islam terdiri atas enam macam : Al Qur'an, As Sunnah, Kata-Kata sahabat, Kemasyarakatan Sosial, Nilai-nilai dan adat kebiasaan masyarakat dan Hasil pemikiran para pemikir Islam (Mujib, 1993).

Pendidikan Islam perspektif Islam berkemajuan juga termotivasi oleh misi Muhammadiyah untuk kehidupan umat dan bangsa yaitu: Menegakkan tauhid yang murni, Menyebarkan ajaran Islam yang bersumber kepada Al Qur'an sebagai kitab Allah yang terakhir untuk manusia dan As Sunnah, Mewujudkan amalan-amalan Isslam dalam kehidupan perseorangan, keluarga dan masyarakat dan Pemahaman agama dengan menggunakan akal pikiran (Nashir et al., 2000). Pendidikan Islam berkemajuan menjadikan misi Muhammadiyah tersebut sebagai landasan pelaksanaan pendidikan Islam. Selain itu pendidikan Islam perspektif Islam berkemajuan juga termotivasi oleh pandangan bahwa manusia akan mampu mencapai derajat keimanan dan ketaqwaan yang sempurna, apabila mereka memiliki kedalaman ilmu pengetahuan dan ketaqwaan sejati hanya akan diraih mereka yang berilmu pengetahuan. Hal tersebut yang menjadi landasasn atau dasar dari pendidikan Islam perspektif Islam berkemajuan serta perlunya menyebarkan ajaran Islam melalui pendidikan Islam.

Komponen Pendidikan dalam Perspektif Islam berkemajuan menurut Muhammadiyah memiliki tujuan secara normative diarahkan untuk mencapai maksud dan tujuan persyarikatan. Dalam Anggaran Dasar Muhammadiyah pasal 4 ayat 1 dan pasal 6, Maksud dan tujuan Muhammadiyah adalah menegakkan dan menjunjung tinggi agama Islam sehingga terwujud masyarakat Islam yang sebenar-benarnya. Karena setiap apa yang dilakukan sejatinya ada tujuan yang ingin dicapai, begitu juga dengan pendidikan. Tujuan pendidikan dan pengajaran Islam disekolah Muhammadiyah yaitu untuk membentuk manusia muslim yang cakap, berakhlak mulia, percaya pada diri sendiri dan berguna bagi masyarakat. Namun tidak hanya membentuk manusia yang memiliki intelktual belaka, melainkan juga manusia muslim, manusia moralis, manusia kolektivis dan manusia yang berwatak atau berkarakter (Salam, 2009).

Beberapa tujuan pendidikan Islam menurut Muhammadiyahyaitu:pertama,mendidik manusia memiliki kesadaran ketauhidan (spiritual makrifat) terhindar dari penyakit masyarakat seperti : Syirik, Khurafat, Bid'ah (Darban \& Pasha, 2000). Kedua, membentuk manusia 
berkemajuan yang memiliki etos tajdid, berfikir cerdas, alternative, dan berwawasan luas. Ketiga, Membina peserta didik agar menjadi manusia yang memiliki IMTAQ (iman dan taqwa), kecakapan hidup, ketrampilan social dan IPTEKS (ilmu Pengetahuan Teknologi Komunikasi dan Seni). Keempat, Membimbing peserta didik agar menjadi manusia yang memiliki jiwa, kemampuan menciptakan dan mengapresiasi karya seni-budaya. Kelima, Membentuk kader yang berkarakter, yang peduli dan peka serta bertanggungjawab terhadap masyarakat dan lingkungan. Dari beberapa tujuan diatas, hakikatnya tujuan pendidikan Islam berkemajuan terfokus pada tiga bagian: Pertama, terbentuknya insan al kamil (manusia paripurna) yang memiliki akhlak qurani, insan yang beriman, berwawasan, bijaksana dan meiliki sifat-sifat yang tercermin dalam pribadi nabi Muhammad SAW. Kedua, terciptanya insan yang kaffah dalam dimensi religious, budaya dan ilmiah. Ketiga, penyadaran tugas seorang manusia sebagai hamba Allah SWT dan sebagai wakil Allah dimuka bumi dan mampu menjadi hamba yang berkemajuan dan tangguh. Dalam pelaksanaan yang sangat diperhatikan baik dari siswa, guru, metode evaluasi, pembiayaan dan kurikulum pendidikan Islam berkemajuan tentu menerapkan konsep pembaharuan-pembaharuan.

Beberapa pembaharuan yang dapat dilakukan untuk mewujudkan pendidikan Islam perspektif Islam berkemajuan yaitu; (1) Mendirikan lembaga pendidikan yang menuju pad integrase keilmuan Islam dan umum, yang tidak mealhirkan dikotomi ilmu. Jadi ilmu agama dan ilmu umum bisa diberikan secara terpadu kepada peserta didik; (2) Memberikan tambahan pelajaran agama pada sekolah-sekolah yang sekuler; (3) Pendidikan Muhammadiyah yang berupaya mengintegrasikan anatara sistem pesantren dan sekuler dalam bentuk lembaga sekolah; (4) Adanya intensifikasi terhadap pemahaman dan penggunaan Bahasa asing (Inggris dan Arab) sebagai alat dalam mengumpulkan pengetahuan ditengah arus berkembangnya zaman; (5) Dari sisi lingkungan juga berpengaruh terhadap kesuksesan pelaksanaan pendidikan karena ada tiga tempat yakni lingkungan keluarga, Sekolah dan masyarakat. Kesemua ini harus saling dukung mendukung untuk tercapainya cita-cita terwujudnya generasi yang terbaik berupa manusia insan kamil.

\section{KESIMPULAN}

Pendidikan Islam berkemajuan dalam perspektif Muhammadiyah merupakan pendidikan Islam yang mengintegrasikan ilmu pengetahuan dengan Islam. Pendidikan yang mengintegrasikan agama dalam kehidupan membentuk perpaduan yang holistik antara iman dan kemodernan. Konsep pendidikan Islam berkemajuan adalah refleksi nilai-nilai humanisasi, liberasi dan transendensi dari kandungan Q.S Ali Imran ayat 104 dan 110 yang secara historis merupakan bagian dari latarbelakang berdirinya Muhammadiyah.

Pendidikan Islam perspektif Islam berkemajuan adalah pendidikan pencerahan kesadaran ke-Tuhanan (makrifat iman/tauhid) yang menghidupkan, mencerdaskan, dan membebaskan manusia dari kebodohan dan kemiskinan bagi kesejahteraan dan kemakmuran manusia dalam kerangka kehidupan berbangsa dan tata pergaulan dunia yang terus berubah dan berkembang, 
sesuai teologi yang dimaksud dalam Surah Al-Maun. Hakikat tujuan pendidikan Islam berkemajuan terfokus pada tiga bagian: Pertama, terbentuknya insan al kamil (manusia paripurna) yang memiliki akhlak qurani, insan yang beriman, berwawasan, bijaksana dan meiliki sifat-sifat yang tercermin dalam pribadi nabi Muhammad SAW.

\section{REFERENSI}

Abdullah, M. S. T. M. I., Kalil, M. S., Wan Daud, W. R., Mohammad, A. B., \& Abd Rahman, R. (2001). Aktualisasi Konsep Dasar Pendidikan Islam.

Daradjat, Z. (2017). Ilmu Pendidikan Islam. Bumi Aksara.

Darban, A. A., \& Pasha, M. K. (2000). Muhammadiyah sebagai Gerakan Islam: Dalam Perspektif Historis dan Ideologis. Pustaka Pelajar.

Hanipuddin, S. (2020). PENDIDIKAN ISLAM BERKEMAJUAN DALAM PEMIKIRAN HAEDAR NASHIR. Insania: Jurnal Alternatif Kependidikan Islam, 25(2), 305-320.

Mubaroq, A. I., Maulana, A., \& Basri, H. (2020). KONSEP PENDIDIKAN ISLAM DALAM PERSPEKTIF KIAI HAJI AHMAD DAHLAN. TAMADDUN, 20(2), 91-102. https://doi.org/ 10.30587/tamaddun.v20i2.1305

Muhammadiyah, P. P. (2010). Tanfidz Keputusan Muktamar Satu Abad Muhammadiyah. Pimpinan Pusat Muhammadiyah.

Mujib, M. A. (1993). Pemikiran Pendidikan Islam: Kajian Filosofis dan Kerangka Dasar Operasionalisasinya. Penerbit Trigenda Karya.

Nashir, H., Nasri, I., \& Ismoyo, W. (2000). Revitalisasi Gerakan Muhammadiyah. BIGRAF Pub.

Nata, A. (2005). Tokoh-tokoh pembaruan pendidikan Islam di Indonesia. P.T. Rajagrafindo Persada.

Rohyani, E. S. (2015). Pemikiran Pendidikan Agama Islam dalam Perspektif Prof. Achmadi. MUDARRISA: Journal of Islamic Education, 5(2), 173-200. https://doi.org/10.18326/ mdr.v7i2.173-200

Rosyadi, K., \& Kuswaidi, S. (2004). Pendidikan profetik. Pustaka Pelajar.

Salam, J. (2009). KH Ahmad Dahlan: amal dan perjuangannya. Al-Wasat Publishing House.

Tafsir, A. (2010). Filsafat Pendidikan Islami; Integrasi Jasmani, Rohani, dan Kalbu. P.T. Remaja Rosdakarya. 